\title{
EL NOROESTE DE LA PENÍNSULA IBÉRICA EN LA EDAD DEL HIERRO: ¿UNA SOCIEDAD PACÍFICA?*
}

\author{
FRANCISCO JAVIER GONZÁLEZ GARCÍA \\ LPPP-IIT-USC \\ Unidad Asociada IEGPS (CSIC-XuGa) ${ }^{* *}$
}

\begin{abstract}
Resumen
La investigación arqueológica sobre la cultura castrexa ha venido elaborando, durante las dos últimas décadas, una imagen de la sociedad de la Edad del Hierro del NO peninsular como un mundo fundamentalmente pacífico. En el presente artículo, a través de la revisión de una serie de materiales arqueológicos (armas, cascos, murallas) y de su contraste con las noticias que nos ofrecen los autores antiguos, se realiza una crítica a esta interpretación pacífica de dicha sociedad con la finalidad de recuperar la actividad bélica como uno de los elementos que nos permiten comprender la sociedad del mundo castreño del NO de la Península.
\end{abstract}

\section{Palabras clave}

Cultura Castrexa, Edad del Hierro, Guerra, Armamento, Murallas.

\begin{abstract}
Since the 80's-90's up to nowadays, archaeological research has represented the hill-forts Iron Age society from Northwestern Iberian peninsula (Cultura castrexa) as a peaceful world. This paper reviews some archaeological items (weapons, helmets and hill-fort walls) and compares them with what can be known from Greek and Roman written sources. Its aim is to criticize that hypothesis and to reintroduce war as a basic element to understand the Iron Age world of this Iberian territories.
\end{abstract}

\section{Key Words}

NW Iberian peninsula, Hill-forts, Iron Age, War, Weapons, Hill-fort Walls.

\footnotetext{
* El presente artículo es una versión ampliada de algunas ideas expuestas en una conferencia pronunciada en mayo del 2004 en la Facultad de Humanidades del Campus de Ourense de la Universidade de Vigo. Quiero expresar mi agradecimiento para con mis anfitriones por haberme ofrecido la posibilidad, en dicha ocasión, de presentar públicamente y someter a discusión algunos de los argumentos que hoy se exponen en las presentes páginas.

** Investigador Contratado. (Programa Isidro Parga Pondal. Xunta de Galicia). Laboratorio de Patrimonio, Paleoambiente e Paisaxe. Instituto de Investigacións Tecnolóxicas. Universidade de Santiago de Compostela. Unidade Asociada: Instituto de Estudios Galegos Padre Sarmiento (Consejo Superior de Investigaciones Científicas - Xunta de Galicia). E-mail: fjavigg@usc.es
} 
«Porque si la ciudad de los lacedemonios fuese devastada y subsistieran solamente sus templos y las plantas de sus edificios, creo yo que entre las generaciones venideras se suscitarían, pasado el tiempo, serias dudas de su poder al compararlo con su fama».

(TuCíDIDEs, Historia de la guerra del Peloponeso, I, 10).

La idea que sobre la cultura castreña del NO nos ofrecen las principales obras de síntesis existentes en la actualidad se caracteriza fundamentalmente por recurrir, casi en exclusividad, al dato arqueológico para intentar reconstruir dicha sociedad. A partir del hecho de que el registro arqueológico muestra pocas diferencias, dentro de los castros, en lo que se refiere al tamaño de las viviendas, técnicas constructivas, a la similar capacidad de almacenamiento de las diversas unidades domésticas, a la dispersión, por igual, en todo el yacimiento de la cerámica, las fíbulas, las joyas, etc., se tiende a hablar de cierto igualitarismo social dentro del mundo castreño. Estaríamos, por tanto, ante una sociedad en la que, en apariencia, no parecen existir demasiadas formas de desigualdad. Una sociedad, por tanto, en la que, aparentemente, los datos arqueológicos no permiten entrever una organización social muy compleja, si bien, para algunos autores, sí que existen indicios de una muy débil jerarquización. Estaríamos, por tanto, ante una sociedad campesina relativamente jerarquizada, organizada en pequeñas comunidades, entre las que tampoco existiría una gradación jerárquica, cerradas sobre sí mismas y casi autárquicas ${ }^{1}$.

Esta descripción general de la sociedad castreña del NO resulta muy adecuada para criticar el modelo de sociedad guerrera que proponen los defensores del recurso a la comparación con el mundo céltico para intentar comprender la Edad del Hierro del NO peninsular ${ }^{2}$. De este hecho deriva, precisamente, la fijación sistemática, por parte de estos autores, de negar la presencia de elites guerreras al frente de la

\footnotetext{
${ }^{1}$ Hemos resumido, aquí, los argumentos expresados en algunas de las obras de síntesis más recientes sobre la cultura castrexa: Calo 1993, 177; Sánchez-.Palencia (ed.), 2000, 108 y Peña 2003, 118. No obstante, la nómina de trabajos que defienden este tipo de planteamientos es muy amplia: Peña 1992, 1996, 1997; Bello Diéguez \& Peña 1995, 158 ss.; Calo 1997; Sastre Prats, 2001, 63 ss..

${ }^{2}$ La negación del carácter belicoso del mundo castrexo está, en realidad, íntimamente vinculada a la negación del componente céltico dentro de la sociedad de la Edad del Hierro del NO, hasta tal punto que podemos llegar a afirmar que se trata de dos facetas de un mismo problema. El carácter belicoso de las sociedades de la Edad del Hierro del NO de la Península no se niega, realmente, porque no existan indicios del mismo, sino porque aceptar dicho carácter implica «integrar el mundo castreño en modelos teóricos pancélticos» (Bello Diéguez \& Peña Santos 1995, 164). Esta vinculación entre negación del componente céltico y de la belicosidad de la sociedad de la Edad del Hierro no se manifiesta, por ejemplo, en otras tradiciones arqueológicas europeas como la británica, en la que autores críticos con el celtismo tradicional, como James (1999), aceptan, sin embargo, el carácter belicoso de las poblaciones británicas prerromanas (James \& Rigby 1997, 58-59).
} 
sociedad castreña ${ }^{3}$. Para ello se recurre a la homogeneidad que presenta el registro y a la ausencia casi total, se asevera, de armas o de tumbas de guerreros, afirmando, con ello, que no existe ese componente bélicoso ${ }^{4}$. Procedamos a analizar estas objeciones. Con respecto a la ausencia de tumbas de guerreros, como las grandes tumbas que aparecen en Europa central, no vamos a entrar en la cuestión, dado que en la actualidad no se conocen necrópolis castreñas y no por ello se duda que los castros hayan estado habitados 5 .

Pasemos, por tanto, a la segunda objeción: las armas. La verdad es que, como vamos a ver, sí que existen armas, no muchas en realidad, pero sí algunas. Esta escasa representación del armamento dentro del registro de la Edad del Hierro en el NO se debe poner en relación, fundamentalmente, con la ausencia de necrópolis dentro del ámbito de la cultura castreña, pues, dentro del conjunto de Europa en la Edad del Hierro, es en este tipo de yacimientos donde suelen aparecer las armas ${ }^{6}$. Dejando a un lado este importante hecho, que explica la escasa presencia del armamento en el NO, mi interés en las presentes páginas radica en demostrar que el objetivo fundamental de esta corriente de la investigación se centra en intentar negar cualquier elemento que pueda introducir el componente bélico dentro del mundo castreño pues éste, en realidad, no cuadra bien con la lectura del registro que realizan dichos autores ${ }^{7}$.

\footnotetext{
${ }^{3}$ Por el contrario, los arqueólogos portugueses, que cuentan con un registro similar al de los arqueólogos gallegos, no dudan a la hora de hablar sobre la existencia de jefaturas guerreras, de elites guerreras que se encargaban de gobernar a las comunidades castreñas: Martins \& Jorge 1992, 367-368.

${ }^{4}$ Calo 1993, 99; Peña 2003, 108. Este planteamiento obvia, evidentemente, un hecho sobradamente conocido por la arqueología y que ha sido recientemente señalado por Guilaine \& Zamnit 2002, 19: que los conflictos bélicos prehistóricos, por su extensión limitada, no siempre dejan trazos visibles a partir de testimonios materiales antiguos.

${ }^{5}$ Con respecto al problema del desconocimiento de las formas de enterramiento en la cultura castrexa ver: Vilaseco Vázquez 1999 y Bettencourt 2000.

${ }^{6}$ Lorrio 1993, 291, 296 y 311, pues, tal y como ha señalado este mismo autor, «los hallazgos de armas en contextos de hábitat no son tan habituales» (Lorrio 1993, 297). Con respecto a esta cuestión véase, también, Cabré de Morán \& Baquedano Beltrán 1997, 241. Un buen ejemplo de la importancia que presenta el armamento dentro del ajuar de las necróplis en la Hispania céltica lo ofrece el análisis que de este tipo de equipamiento y de yacimiento ha realizado, para el área vetona, Álvarez Sanchís 2003,81 ss. En algunas áreas europeas, como la Galia, los santuarios son la otra gran fuente de información sobre el armamento de la Edad del Hierro (Brunaux \& Lambot 1987, 14-16), si bien, para el caso de la Península, apenas existen, lamentablemente, referencias a hallazgos de armas en santuarios (Lorrio 1993, 302).

${ }^{7}$ En otros contextos europeos de Edad del Hierro, como Irlanda, tampoco aparecen muchas armas, de hecho Raftery 1994, 141-146, sólo señala la existencia de treinta espadas y dos escudos, entre otros materiales bélicos, en toda Irlanda y, sin embargo, esta ausencia de material arqueológico vinculable con la actividad guerrera no ha llevado a los arqueólogos irlandeses a defender el carácter pacífico de las poblaciones insulares de la Edad del Hierro.
} 
Analicemos, en primer lugar, la cuestión de las armas. Sabemos que en diversas excavaciones realizadas en castros de Galicia y el Norte de Portugal han aparecido armas; por citar sólo unos pocos ejemplos, podemos mencionar: los tres puñales afalcatados de Sanfins, los dos de San Juliâo, o los fragmentos aparecidos en Baroña; las puntas de lanza (Sanfins, Briteiros, Carvalhelhos o Castro Máximo), si bien hay que señalar que se trata de materiales de cronología tardía. O también los puñales de antenas aparecidos en San Cibrán das Las y Viladonga o el umbo de escudo (de tipo La Tène II) descubierto en Alvarelhos ${ }^{8}$.

Esta escasez de armas del registro castrexo puede der debida, además de a la ausencia de necrópolis, al carácter del suelo gallego, muy poco apropiado para la conservación del metal, tal y como lo demuestra el hecho de que tampoco son muchos los aperos metálicos de labranza que se conservan del mundo castrexo 9 . Esta característica edafológica no parece ser tenida en cuenta por estos autores pues, con esos mismos argumentos, también se podría negar que los castrexos fuesen agricultores o, al menos, que utilizasen el metal en las prácticas agrícolas, duda que, evidentemente, nunca se plantea. Los textos nos informan del carácter belicoso de los pueblos prerromanos del NO pero, como lo que se intenta, por parte de esta corriente de la investigación, es negar el componente bélico de los mismos, se echa mano de un argumento ya conocido, «las fuentes antiguas mienten» ${ }^{10}$, y, de ese modo, se afirma que este tipo de noticias sólo pretende resaltar el valor de la conquista romana, que tuvo que hacer frente a enemigos aguerridos ${ }^{11}$.

Ahora bien, las fuentes nos ofrecen, para el caso de los lusitanos, vecinos de los galaicos, una descripción de su armamento:

«Se dice que los lusitanos están dotados para las emboscadas y el espionaje, que son rápidos, despiertos y hábiles para la retirada. Poseen un escudo pequeño, de dos pies de diámetro y cóncavo por su parte delantera, que llevan colgado de los hombros con ayuda de correas, pues, al parecer, carece de abrazaderas y de asas. Además de dichos escudos también van armados con un puñal o cuchillo. La mayoría de ellos llevan corazas de lino y sólo unos pocos usan corazas de cota de malla y cas-

\footnotetext{
${ }^{8}$ Relación tomada de Calo 1993, 127-128. La nómina de armas descubiertas en contextos castreños es superior a la aquí ofrecida, ver, por ejemplo, González Rubial 2003, 186-191 y 356-363. Para un estudio de conjunto del armamento de la Edad del Hierro en el NO todavía debemos remitirnos lamentablemente, a falta de trabajos más recientes y actualizados, a López Cuevillas 1947 y López Cuevillas 1989, 173-194.

${ }^{9}$ Cuarenta y uno, en total, según señala Teira Brión 2003, 172-173.

${ }^{10}$ Con respecto a esta consideración de las fuentes literarias que informan sobre el NO prerromano ver González García (en prensa).

${ }^{11}$ Acerca de estas noticias sobre la belicosidad de las poblaciones hispanas del área indoeuropea véase Ciprés 1993 y García Huerta 1997.
} 
cos con tres cimeras, usando, el resto, cascos hechos con nervios. Los soldados de infantería también utilizan espinilleras [knémides], poseyendo cada soldado varias jabalinas, mientras que algunos otros usan lanzas con puntas de bronce» (Estrabón, Geografía III, 3, 6).

Casualmente, parte de este armamento está confirmado arqueológicamente a través de la panoplia representada en los denominados «guerreiros galaico-lusitanos» (Figura 1). Se trata de estatuas, bastante toscas, en las que se representa a un guerrero con «torques sobre o pescozo, corpo cuberto con túnica de manga curta ata metade do muslo-o sagum ( sic) cinxida cun cinturón máis ou menos complicado, brazos con brazaletes -os viria- e pulseiras, pernas robustas con caneleiras... As armas destes guerreiros son o pequeño escudo circular -moi frecuente no ámbito mediterráneo da época e coñecido co nome latino de caetra- e un puñal ou espada curta de características arcaicas, anacrónicas, sen referentes claros no contexto arqueolóxico» ${ }^{12}$. Pero, claro ésta, este hecho no se tiene en cuenta pues el registro arqueológico, siempre presente para estos autores,

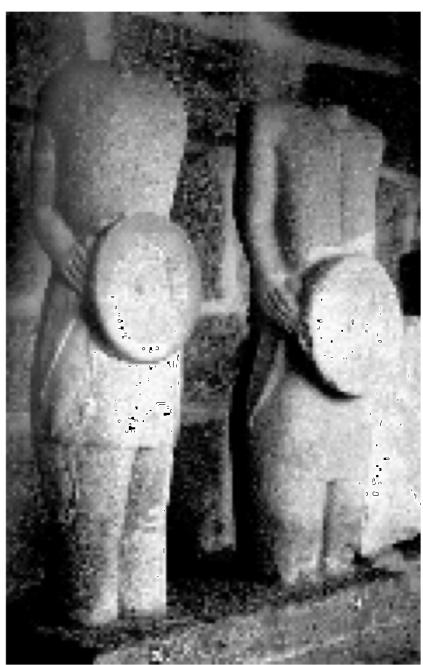

Figura 1. Guerreiros galaico-lusitanos. Museo de Guimarâes (Fuente: Álvarez Sanchís 2003). nos informa que en el mundo castreño no existen diferencias jerárquicas y, por tanto, no puede haber guerreros, entendidos estos, por tanto, como elites o jefes. Estamos, así pues, ante un argumento circular en el que lo que más pesa es el dato arqueológico y, ante él, todo lo demás se tiene que obviar o rechazar.

12 Peña 2003, 175-176. La simple presencia del torques al cuello ya nos estaría señalando que el personaje representado es un guerrero, posiblemente un jefe, o un dios, pues dentro de la Edad del Hierro europea son los jefes guerreros o los personajes divinos quienes, entre los individuos de sexo masculino, lucen este tipo de joya (ver, por ejemplo, Brun 2002, 47, 52-53 y 56; Olivier 2002, 81 y Marco Simón 2002, 69-71). No obstante, recientemente se ha desarrollado otra nueva corriente interpretativa, fruto de la consideración de la sociedad castreña del NO como pacífica, que tiende a interpretar los torques como bienes del grupo que habita en un castro, a modo de segundo gran referente de las comunidades castreñas, a continuación de la muralla; se trataría, por tanto, de un objeto que hace alusión al grupo y a su capacidad económica, hasta tal punto que se afirma que el torques no lo ostenta y exhibe una persona como muestra de su riqueza personal, sino que se entierra y oculta en el entorno del castro, probablemente como sanción de transacciones políticas intergrupales (ver, con respecto a este tipo de interpretación de los torques del NO, Perea 2003, 147-148, cuyos argumentos resumimos aquí). 
¿Qué ocurre, en cambio, si recurrimos a la comparación con otras sociedades del hierro europeo? Pues bien, para el caso de la Galia vemos que las fuentes y la arqueología nos hablan de la presencia de elites, vinculadas con la función guerrera, y que la plástica de esta área nos muestra representaciones muy próximas, si bien de mayor calidad y mejor acabado, que las de los «guerreiros castrexos», representados al modo indígena, con una especie de cota de malla, escudo, torque y espada (Figura 2). Estas estatuas se interpretan como pertenecientes a individuos de la elite social indígena, representados con una serie de elementos que caracterizarían su rango: la panoplia, el torques y, en ocasiones, brazaletes similares a los que vemos en la plástica del $\mathrm{NO}^{13}$.

Para la Galia contamos con César que, pese a que sabemos que era un gran propagandista de sí mismo ${ }^{14}$, es un escollo difícil de salvar a la hora de intentar afirmar que no existían elites guerreras; en cambio, para la Gallaecia carecemos de cualquier fuente similar a César y como el registro no habla sobre diferencias

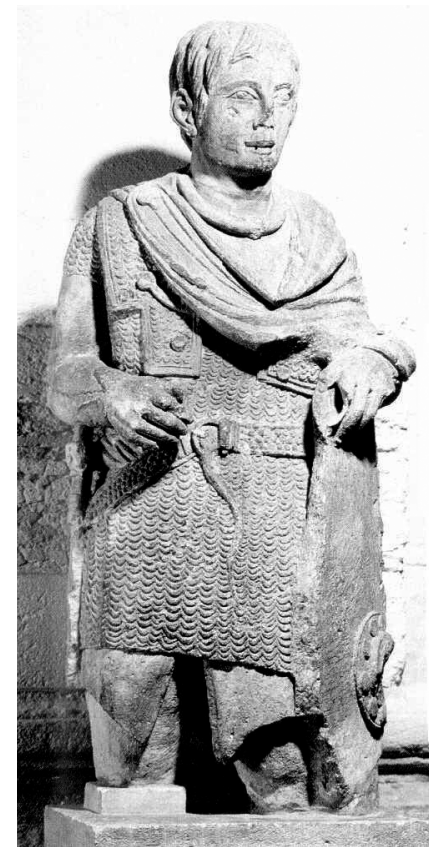

Figura 2. Guerrero galo. Museo Calvet. Avignon, Francia (Fuente: Cunliffe 1997). sociales, algunos autores se creen legitimados para considerar que en el mundo castrexo no podía existir este tipo de personajes y, sin embargo, aparece este tipo de representaciones. ¿Cómo hacer casar estas esculturas de «guerreiros» con esa lectura no jerárquica del registro? Para ello se recurre a concederles una datación tardía, de época romana, y a interpretarlas como representaciones de personajes míticos fundadores del castro o de individuos principales de la comunidad, más o menos mitificados; se trataría, en concreto, de estatuas erigidas en honor de los notables de los castros que colaboraron con Roma, motivo por el que ésta consistió que se alzaran dichos monumentos, para favorecer la situación de prestigio alcanzada por esos individuos que colaboraban con ella ${ }^{15}$. Es lógico que ésta sea la interpretación, pues el registro indica que antes de la conquista romana no había jerarquización social en el mundo castreño; ésta, por tanto, debió ser obra de la conquista y fomentada por la

\footnotetext{
${ }^{13}$ Cunliffe 1997, 107.

${ }^{14}$ La bibliografía con respecto a la Galia, su conquista, el carácter de la sociedad gala y la tendenciosidad de César como historiador es inmensa a modo de aproximación, actualizada y aquilatada, a dichas cuestiones ver Lewuillon 1999.

15 Opiniones expresadas en Calo, 1994, 685-686; Peña 2003, 175-176.
} 
propia Roma. Estamos, de nuevo, ante otro argumento circular: el registro dice que no hay diferencias sociales ni jerarquías y eso es lo que vale, todo lo demás se desprecia recurriendo, para ello, a argumentos $a d$ hoc, incluso a razonamientos tan extraños como los que acabemos de exponer ${ }^{16}$.

Intentaré explicar porqué califico dichos argumentos como extraños. En primer lugar porque estas interpretaciones, en mi opinión, obvian un hecho que me parece fundamental: los «guerreiros» lucen una indumentaria indígena, no romana, lo que, junto con la noticia de Estrabón, viene a demostrar que esas armas eran de tradición autóctona y que, por tanto, eran indicadores de estatus social elevado, al igual que sucede en el caso de los guerreros galos. Además, recurrir a personajes míticos para explicar estas esculturas es, en contra de lo que estos autores puedan pensar, un argumento que no avala, para nada, su argumentación. El mito, lo sabemos gracias a la obra de Lévi-Strauss ${ }^{17}$, juega con la realidad, transformándola y resemantizándola para, a través de esa lógica de lo concreto que lo caracteriza, reflexionar sobre la sociedad. Por tanto un guerrero mítico sólo puede ser pensado si en la realidad los guerreros existían dentro de esa sociedad que los creó y los pensó ${ }^{18}$. Dentro de la ideología de un grupo social sólo pueden tener validez aquellos valores que son socialmente importantes.

En segundo lugar, defender la inexistencia de jerarquías sociales basándose en el registro arqueológico es, desde mi punto de vista, un argumento de una pobreza antropológica extrema. Sabemos que en muchas sociedades tradicionales la riqueza no es algo que se acumula, sino algo que se distribuye, que se da y, a través de ella, los individuos generosos llegan a ser jefes o, al menos, a gozar de prestigio social $^{19}$. Una jefatura, por tanto, no se crea de la nada, como parecen pensar que

${ }^{16}$ En mi opinión, el problema más grave de este tipo de planteamiento viene dado por la situación de aislamiento en que, una vez más, se sitúa a la investigación protohistórica gallega, al negar la posibilidad, para el NO peninsular, de aplicar una serie de hipótesis interpretativas de amplio alcance, tanto cronológico como espacial, sobre el desarrollo de las elites guerreras que se han venido desarrollando en los últimos años tanto en Europa como en España (véase, respectivamente, Kristiansen 1999 y Almagro Gorbea 1997).

${ }^{17}$ Lévi-Strauss 1984.

${ }^{18}$ En este sentido resulta mucho más coherente la interpretación de estas estatuas que ofrece Tranoy 1988, 223, quien, aceptando el carácter belicoso de las poblaciones indígenas del NO, las interpreta no como el retrato de un jefe guerrero en concreto, sino como un medio a través del cual la comunidad del castro afirma su fuerza, como una especie de héroe o divinidad tutelar de la comunidad con la que se podía identificar el jefe del grupo.

${ }^{19}$ A modo de ejemplo general sobre esta forma de jefatura primitiva ver Clastres 1974, 25 ss. Este tipo de jefatura es la que parece reconocerse en el caso de la Hispania indoeuropea, tal y como ha señalado Ciprés 1999, 130-131 para el caso de Celtiberia o Sánchez Moreno 2001 y 2002, con respecto a Viriato y Lusitania. Sobre la caracterización de Viriato como jefe en las fuentes clásicas, véase García Quintela 1999, 179 ss. 
podrían haber hecho los romanos en Gallaecia, sino que se gana, es decir, hay que trabajarla. Me resulta bastante difícil pensar que Roma creó las elites indígenas para poder entrar en contacto con ellas, prefiero pensar, por el contrario, que los romanos fueron capaces de detectar qué individuos eran relevantes en cada comunidad, pese a que dicha relevancia no deje huellas en el registro, y, a partir de ahí, procedieron a contactar con ellos para controlar a los grupos indígenas; algunas de estas elites prerromanas, aquéllas que colaboraron con Roma, se habrían beneficiado, mientras que las que se negaron a colaborar habrían sido represaliadas y sustituidas, dentro de su grupo, por individuos importantes dispuestos a colaborar con Roma ${ }^{20}$. Además, para el caso de Gallaecia conocemos, gracias a la epigrafía, ejemplos de principes, no príncipes, sino individuos principales, destacados, «jefes», como Níger, principis Albionum (ERA, 14), u otro individuo, de nombre desconocido, que figura en un epígrafe de Lugo como princeps de los Cóporos (CIL, II, 2585; IRG, Lugo, 50; IRPL, 34), datados, ambos, en el siglo I d.C. Dada la datación y el hecho de que se trata de epígrafes romanos, los individuos allí mencionados como principes se interpretan como personajes pertenecientes a esa élite fomentada, ¿ex novo? (¿cómo?, me pregunto), por Roma ${ }^{21}$. Estamos otra vez, claro está, ante un argumento circular: el registro manda.

Creo que la correcta interpretación de las relaciones entre Roma y las elites indígenas pasa por la adopción y adaptación, al caso galaico, del concepto de rex amicus de Roma que viene siendo utilizando por la investigación desde hace años ${ }^{22}$. Carecemos, lamentablemente, de cualquier noticia sobre Gallaecia a este respecto pero, por suerte, las fuentes antiguas nos informan sobre ciertos hechos ocurridos en la relación establecida entre Roma y las poblaciones lusitanas que, gracias a las estrechas relaciones entre Lusitania y Gallaecia ${ }^{23}$, podemos extrapolar al área geo-

\footnotetext{
${ }^{20}$ Sobre dicha política de compensación y castigo por parte de Roma en el NO véase Mangas 2000, 53. En este sentido parece apuntar el recientemente descubierto «Edicto del Bierzo», en el que Augusto favorece a los castellani Paemiobrigensis de la gens Susarri con una serie de medidas «por haber permanecido leales mientras los demás hacían defección» (ver Sánchez-Palencia \& Mangas coords., 2000, 19).

${ }^{21}$ En contra de esta opinión se puede argumentar la conclusión de Le Roux 2003, 184, quien, tras analizar la evidencia epigráfica y textual, ha señalado que «il n’y a cependant pas de raison de retenir que les societés des castella ne se hiérarchisèrent qu'avec de la conquête». En este mismo sentido, de aceptación de élites indígenas con anterioridad a la conquista romana, ver Tranoy 1988, 225-226. Con respecto al carácter indígena de estos principes ver García Quintela 2002, 43 ss.

${ }^{22}$ Wells 2002, 121-122; Braund 1984.

${ }^{23}$ Además de las similitudes lingüísticas, religiosas, arqueológicas, etc. entre estos dos territorios, contamos con la noticia de Estrabón (III, 3, 3) que afirma que Lusitania abarcaba todos los territorios del occidente peninsular desde el Tajo hasta el Cantábrico, pasaje que, por tanto, parece dar cuenta de una situación anterior a la época de la conquista y creación de la provincia de Lusitania por Roma y
} 
gráfica situada al $\mathrm{N}$ del Duero. Se trata, en concreto, de las noticias recogidas por Apiano $^{24}$ con respecto al tratado firmado en 140 a.C. por Q. Fabio Máximo Serviliano y Viriato ${ }^{25}$, por el que éste último era reconocido como amigo del pueblo romano, denominación que, como ha señalado Braund, era la fórmula a través de la cual se reconocía, durante el período republicano romano, la condición de «cliente» $\mathrm{o}$ de aliado de Roma ${ }^{26}$.

Volvamos a las armas, que hemos dejado un poco olvidadas, y, en concreto, a los puñales. Como ya vimos, en el registro castreño del NO aparecen puñales pero, como cabía esperar, estos autores consideran que no son armas de verdad. En su opinión, para el caso de los modelos de puñales de antena castrexos no podemos hablar, ni por su forma, poco adecuada, ni por su pequeño tamaño, ni por el material poco resistente en que están fundidos, ni, en suma, por sus poco eficaces características técnicas, de auténticas armas, sino de elementos de prestigio para exhibición y ostentación de rango y poder ${ }^{27}$. No parecen ser, por tanto, verdaderas armas sino puñales de parada que sirven para prestigiar a un individuo; ahora bien, ¿cómo puede alcanzar prestigio una persona a través de la posesión y porte de un arma si la guerra no es una actividad prestigiosa dentro de los valores de la sociedad en que vive dicho individuo? En mi opinión, resulta muy dudoso que un objeto sin valor social pueda servir de elemento de prestigio ${ }^{28}$.

en la que las posteriores Lusitania y Gallaecia formaban una misma unidad. Para una aproximación crítica a las noticias de este pasaje estraboniano ver: Pérez Vilatela 2000, 57 ss., en especial 65-70.

${ }^{24}$ Iber., 69-70; noticias menos extensas sobre dicho acuerdo las ofrecen Diod. Síc. XXXIII, 1, 4 y Tito Livio, per. LIV.

${ }^{25}$ Sobre dicho tratado ver Ciprés 1993, 157 y, de forma más extensa y detallada, García Riaza 2002, 149-159.

${ }^{26}$ Braund 1984, 23-24.

${ }^{27}$ Peña 2003, 170. Con respecto a estas características del armamento castrexo ver: Brañas \& Comendador 2003, 33-34, quienes también señalan el posible carácter votivo de estas piezas, lo que quizás permitiría vincularlas a prácticas rituales características de Edad del Bronce, como las ofrendas a cursos fluviales o aguas (sobre esta práctica véase Meijide Cameselle 1988, 79-87).

${ }^{28} \mathrm{Se}$ conocen diversas armas de parada en distintos contextos de la Edad del Hierro tanto europea (por ejemplo, en la Galia: Brunaux \& Lambot 1987, 85 ss.), como peninsular (así, por ejemplo, en las culturas de la Edad del Hierro de la Meseta o de Celtiberia: ver Baquedano Beltrán \& Cabré de Morán 1997). El factor común a todos estos contextos arqueológicos viene dado por el hecho de que, en ellas, la guerra parece haber tenido un importante valor social. Generalmente se trata de objetos valiosos, ricamente decorados y realizados en costosos materiales y con complejas técnicas metalúrgicas. Dado el carácter suntuoso de estas piezas, su carácter como objetos de gran valor, lo cual no parece ser el caso de las piezas galaicas, tradicionalmente se ha venido considerando que no se trata de armas con utilidad militar, argumento que, en la actualidad, tiende a ser rechazado por algunos investigadores (véase, por ejemplo, para la Península: Quesada Sanz 1997a, 200-201; con respecto a Gran Bretaña: James \& Rigby 1997, 58). 
Por lo demás la inadecuación del material, su escasa resistencia, para desempeñar una función bélica no es un argumento totalmente decisivo, ni tampoco implica una merma en el carácter belicoso de un pueblo. La guerra se hace con los materiales que se tienen a disposición, de tal modo que resulta muy poco importante la utilidad y funcionalidad que las armas utilizadas puedan tener para nosotros. La guerra o, mejor, la forma de hacer la guerra no es universal, sino que varía entre culturas dependiendo en gran medida, como señaló Keegan ${ }^{29}$, de diversas variables, entre ellas la configuración social y, en gran medida, la tecnología. Por ello, aplicar nuestros criterios tecnológicos a la forma de guerrear de pueblos de hace más de dos mil años no sólo es erróneo sino que, además, es un planteamiento carente de cualquier rigor histórico.

La cuestión de la funcionalidad del armamento castreño del NO nos permite, además, realizar un excurso sobre la correcta utilización de las noticias que nos ofrecen las fuentes antiguas. Con los textos clásicos en la mano podríamos argumentar que la endeblez de los puñales no tiene ninguna importancia, pues contamos con una noticia de Polibio (II, 33,3) que nos informa sobre la fragilidad de las espadas galas:

«En peleas anteriores habían observado que todos los linajes galos son muy temibles y arrojados en el inicio del ataque mientras todavía están intactos. Se ha notado ya que, por su construcción, las espadas galas sólo tienen eficaz el primer golpe, después del cual se mellan rápidamente, y se tuercen de largo y de ancho de tal modo que si no se da tiempo a los que las usan de apoyarlas en el suelo y así enderezarlas con el pie, la segunda estocada resulta inofensiva» (trad. M. Balasch Recort).

Si utilizásemos este tipo de argumentación estaríamos, en realidad, haciendo un uso erróneo de nuestra fuente y, al mismo tiempo, faltando al rigor histórico, pues sabemos, gracias a la arqueología, que las espadas de los galos no se doblaban ni mellaban con la facilidad que Polibio nos informa, sino que eran, por el contrario, instrumentos muy resistentes ${ }^{30}$. Esta noticia, como demostró Reinach a principios del siglo $\mathrm{XX}^{31}$, es, en realidad, un error de interpretación por parte del historiador griego, fruto de la posible contemplación de necrópolis galas, con enterramientos dotados con ajuares en los que, siguiendo un rito celta muy frecuente, se habrían incluido espadas inutilizadas tras haber sido dobladas. Estas necrópolis habrían sido consideradas como cementerios vinculados con antiguos campos de batalla, de

\footnotetext{
${ }^{29}$ Keegan 1995.

${ }^{30}$ Brunaux \& Lambot 1987, 88.

${ }^{31}$ Reinach 1996, 313-315.
} 
ahí el error de interpretación: se creía que las espadas que aparecían en las tumbas de los guerreros galos eran, en realidad, las que habían utilizado en el combate y, por tanto, que la deformación de dichas piezas había sido consecuencia de su uso durante el enfrentamiento y de su escasa resistencia ${ }^{32}$.

Otro ejemplo de material bélico que ha sido desprestigiado por parte de estos autores lo ofrece un conjunto de cinco cascos de bronce encontrados en el área meridional de la cultura castrexa (sur de Galicia y norte de Portugal ${ }^{33}$ ) que presentan guardanucas decorados con motivos geométricos similares a los de la cerámica indígena y que se interpretan como adaptaciones locales de un modelo muy común en el Mediterráneo central europeo -principalmente del N de Italia- y que fue utilizado por la infantería romana de época republicana ${ }^{34}$ (Figura 3). Se trata de un tipo de casco que se conoce como Montefortino y que, si bien es cierto que fue usado por el ejército romano, también sabemos que fuente utilizado por poblaciones célticas ${ }^{35}$. Ahora mismo poco importa, realmente, el carácter céltico o no de la población indígena que pudo utilizar estos cascos descubiertos en el Norte de Portugal y el Sur de Galicia. El interés que presentan estas piezas viene dado por el hecho de que la coincidencia entre la decoración de dichos cascos y la de la cerámica indígena parece indicar que estos cascos son producciones locales, quizás desarrolladas a partir de los tipos Montefortinos del ejército romano. La datación de estos cascos, realizada a partir del material asociado a ellos, parece indicar que se trata de producciones de época anterior a Augusto, posiblemente de la segunda mitad del siglo I a. $C^{36}$. No podemos pensar, por tanto, que se trata de piezas realizadas por indígenas para el abastecimiento del ejército romano, pues nos movemos dentro del ámbito cronológico en que se desarrolló la conquista de estas regiones por Roma y, por ello, cabe pensar que sus usuarios fueron galaicos, tal y como parece indicarlo el torso de guerrero, tocado

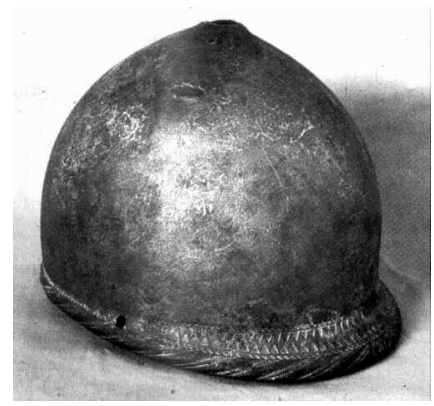

Figura 3. Casco tipo Montefortino. Museo Diocesano de Tui (Fuente: Peña 2003).

\footnotetext{
32 Esta explicación sigue siendo aceptada en la actualidad por la investigación arqueológica, ver, por ejemplo, Cunliffe 1997, 94.

${ }^{33}$ Cuatro de estas piezas aparecieron en Portugal (dos de ellas en Castelo de Neiva, una en Briteiros y otra en Lañoso) y una en Galicia (en Caldelas de Tui, Pontevedra, durante el dragado del Miño): Lorrio 1993, 300.

${ }^{34}$ Peña 2003, 170.

35 Gracia Alonso 2003, 207; Quesada Sanz 1997b, 151-154; Brunaux \& Lambot 1987, 102-106.

${ }^{36}$ Quesada Sanz 1997b, 159.
} 
con casco, de Sanfíns (Figura 4) ${ }^{37}$. Así pues, si los indígenas usaban cascos militares era porque, entre ellos, alguna importancia tendría la actividad bélica. Por lo demás, el uso de cascos de bronce en otros contextos de la Edad del Hierro europea, como las poblaciones galas prerromanas, no era una práctica generalizada entre los guerreros, sino que se trataba de piezas usadas por príncipes o jefes, eran objetos de prestigio, signos distintivos de una clase social superior ${ }^{38}$. En este sentido, por tanto, el material arqueológico que aparece en el NO parece ofrecer indicios de la existencia de una elite guerrera.

Existe, por último, un dato que se suele despreciar por parte de esta corriente interpretativa del mundo castrexo: la utilización generalizada de individuos procedentes del $\mathrm{NO}$ en las unidades auxiliares del ejército romano ${ }^{39}$. De hecho, se conocen 14 unidades auxiliares reclutadas, en origen, entre poblaciones de los conventos lucense y bracarense ${ }^{40}$.

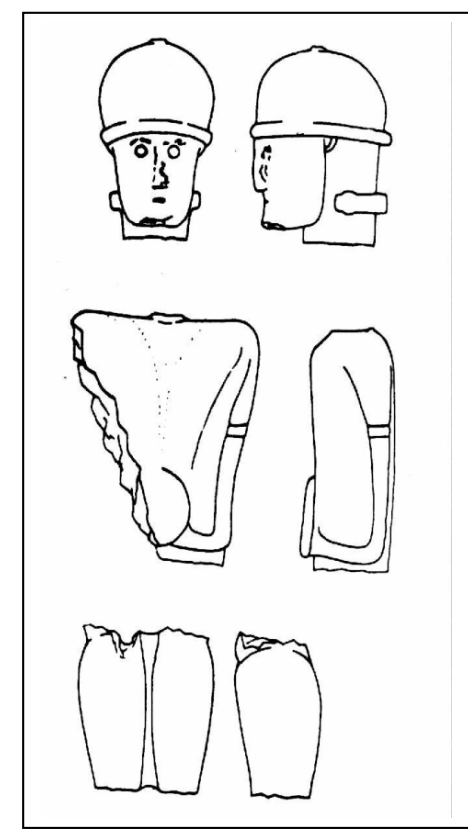

Figura 4. Estatua de guerrero fragmentada. Citania de Sanfins (Fuente: Stary 1982).

Pasemos ahora al último argumento para negar el carácter belicoso o, al menos, la importancia de la actividad guerrera entre las poblaciones del NO prerromano. Nos detendremos, por tanto, en la interpretación que sobre las murallas de los castros ofrecen estos autores para, a continuación, tomando como ejemplo una de esas posibles funciones no defensivas de la muralla, intentar demostrar que es muy posible que dicha función, en realidad, tenga que ver con una serie de valores estrechamente relacionados con la guerra.

${ }^{37}$ Stary 1982, 118-119. Dicha pieza, en opinión de Tranoy $(1988,221)$ confirma el carácter militar de los personajes representados en estas estatuas.

${ }^{38}$ Tal y como señalan Bruneux \& Lambot 1987, 104.

39 Tal y como señaló García Quintela en Vázquez Varela \& García Quintela 1998, 158 ss. y en García Quintela 1999, 291-295. Con respecto al servicio de galaicos en estas unidades, Tranoy (1988, 225) ha indicado la posibilidad de que las estatuas de guerreros galaicos con inscripciones epigráficas sean, como consecuencia de ciertas diferencias iconográficas con respecto a las estatuas anepígrafas, ejemplos de exaltación del poder de un individuo indígena concreto cuyo prestigio se vio refrendado por haber servido como auxiliar en el ejército romano.

${ }^{40}$ Santos 1988, 119 ss. Con respecto al reclutamiento de indígenas en las unidades auxiliares ver Le Bohec 1990, 97-103 y, para el caso concreto de los indígenas hispanos, Roldán Hervás 1997, 299 ss. 
Dado que las murallas más importantes, y mejor construidas de los castros del NO, se realizaron en época romana, estos autores tienden a considerar que su función no podía ser defensiva, pues en esa época Gallaecia vivía dentro del ámbito de la pax romana. Así pues, las murallas habrían nacido, en opinión de algunos de estos autores, con una finalidad defensiva pero, una vez alejado el peligro (tras la conquista romana), se siguieron construyendo para prestigiar a sus moradores, conservando de ese modo una función simbólica. Además de esta función de prestigio, las murallas también actuarían como delimitadoras del espacio habitacional, como medio de control del paso hacia el interior y como protección mágica del recinto. Las murallas, por tanto, permiten la individualización de los castros en el espacio, prestándoles, además, condiciones de habitabilidad y acrecentando su apariencia física. Así pues, parece que la muralla trasciende la intención defensiva primaria y que también cumple una función social, pues dota al grupo de una cohesión social que neutraliza las tendencias disgregadoras. Estas estructuras arquitectónicas de tipo defensivo no tienen porqué manifestar necesariamente, en opinión de estos autores, la presencia de componentes guerreros ni un estado general de conflicto. En realidad, las murallas parecen algo inevitable en todos los procesos de sedentarización y cumplirían otras funciones tanto o más importantes que las fundamentalmente defensivas: neutralizar las posibles tendencias a la dispersión de la comunidad, conceder visibilidad a los poblados, convirtiéndolos en marcas visibles en el paisaje frente a comunidades vecinas, actuar como elementos que servían para definir el status de la comunidad y su importancia, riqueza y prestigio, etc. y, sobre todo, proteger a la comunidad del medio natural exterior claramente hostil y lleno de peligros reales o imaginarios ${ }^{41}$.

Voy a detenerme, precisamente, en esta última función de la muralla, pero antes deseo señalar que la construcción de murallas en los castros de época romana se puede explicar, simplemente, mediante el recurso a una característica general de las sociedades tradicionales: que las cosas se hacen de una manera determinada porque siempre se han hecho así, porque, como afirman muchos indígenas al ser encuestados por los antropólogos, así nos lo enseñaron nuestros antepasados. Es posible, por tanto, que en época romana las murallas ya no tuviesen función defensiva, pese a que es el momento en que, como consecuencia de la influencia de Roma y de los avances técnicos introducidos por ésta en el NO, mejor se construyen, pero ello no

${ }^{41}$ Hemos resumido aquí los argumentos expresado por Calo 1993, 102; Sánchez-Palencia (ed.) 2000, 82; Peña 2003, 126-127. Existen, no obstante, autores para quienes la aceptación de este carácter «polisémico» de la muralla no implica negar su carácter defensivo y la belicosidad de las poblaciones que se protegían tras ellas; véase, por ejemplo, Cerdeño Serrano 1997, 237-238. 
implica que con anterioridad no hubiesen desempeñado, además de otras funciones secundarias, una función principalmente defensiva.

Pasaré ahora a analizar esa funcionalidad de la muralla como medio a través del cual la comunidad se protege del medio natural exterior claramente hostil y lleno de peligros. Esta afirmación implica la consideración de la muralla como un elemento cultural que, al acotar el espacio de habitación del poblado, marca una frontera con el mundo de la naturaleza. El objetivo que aquí me propongo consiste en intentar demostrar que afirmaciones de este tipo son un claro ejemplo de no ver el bosque por prestar mucha atención a los árboles. Es decir, la muralla pudo jugar dicho papel y, al mismo tiempo, ser un elemento defensivo frente a otras comunidades humanas.

Esta lectura del registro arqueológico sólo trabaja a un nivel interpretativo cuya base fundamental, pese a lo que opinan los autores que defienden estas interpretaciones, no radica en realizar una reconstrucción histórica a partir del «dato aséptico» que aporta el material arqueológico ${ }^{42}$, sino que se fundamenta, como ya hemos venido viendo, en una serie de preconceptos, básicamente la hiperpotenciación del dato arqueológico, la defensa del carácter particular y único del fenómeno castreño del NO y, con ello, la negación de cualquier forma de comparación con otras realidades contemporáneas, en tanto que ésta puede implicar un medio de inclusión de componentes célticos en la elaboración de las hipótesis interpretativas. Frente a este planteamiento, a continuación voy a intentar demostrar que el mismo elemento arqueológico (la muralla) se puede leer al mismo tiempo en diversos niveles y que estos, por su parte, se encuentran entre sí íntimamente interconectados, siendo precisamente esta interconexión la que nos permite llegar a comprender el significado del elemento estudiado ${ }^{43}$.

Para ello hay que partir de una afirmación simple y evidente: que la muralla es un elemento construido por la acción humana y que, por tanto, estamos ante un elemento cultural que sirve de delimitador espacial entre naturaleza y cultura.

La muralla delimita el poblado y, desde este punto de vista, marca la ruptura entre la naturaleza y la cultura. No debemos olvidar que estamos ante las primeras

\footnotetext{
42 Peña 2003, 110.

${ }^{43}$ Este intento parte de una serie de consideraciones señaladas por Bermejo 2002, 11 ss., que se basan fundamentalmente en la afirmación de que los monumentos arqueológicos sólo pueden adquirir significado si se les integra dentro del discurso de la historia; es decir, que sirven para conocer el pasado, para reflexionar sobre la sociedad y el pensamiento de los seres del pasado. Se trata, por tanto, de valorar el monumento por su valor cognoscitivo, porque éste posee un significado que nos permite conocer las técnicas constructivas, las relaciones sociales o los valores simbólicos de la sociedad que lo produjo.
} 
poblaciones plenamente sedentarias del NO. Dicha sedentarización se señala, además, a través de la monumentalización de los asentamientos, hecho que nos permite suponer que fue en este momento cuando se produjo un nuevo tipo de paisaje social a través de una compartimentación artificial del suelo, es decir, que se procedió a una nueva plasmación en el espacio de la relación naturaleza-cultura que, en este momento, adoptó una organización mucho mas estable o, al menos, mas fácil de percibir para nosotros que en épocas anteriores ${ }^{44}$.

Pero, antes de avanzar, es preciso que realicemos un pequeño excurso por el mundo íbero y celtibérico. García Quintela ha señalado la posible existencia de una división tripartita del territorio en la organización del espacio entre iberos y celtiberos que consistió en la diferenciación entre un espacio de habitación, un área dedicada a la agricultura y un terreno marginal en el que se desarrollan las actividades bélicas y cinegéticas ${ }^{45}$.

Esta división del espacio entre el asentamiento, los terrenos de cultivo y un espacio natural marginal dedicado a la caza y a la guerra también parece atestiguarse en el caso del mundo castreño del NO. Actualmente se sabe que los castros ocupan un territorio demarcado, acotado, que abarca un área de explotación compuesta por varias unidades productivas ${ }^{46}$. Por otra parte, los modelos hipotéticos (Figura 5) de uso del espacio en época castreña que ha ofrecido Parcero también parecen apuntar hacia una gradación espacial similar entre naturaleza y cultura ${ }^{47}$. Además, las fuentes antiguas nos ofrecen noticias sobre este tipo de compartimentación. Así, por ejemplo, en Dión Casio (LIII, 29, 1-2) leemos lo siguiente:

«Tan pronto como Augusto partió de Hispania, dejando allí a Lucio Emilio como gobernador, los cántabros y astures se rebelaron; enviaron mensajeros a Emilio para, antes de manifestarle su intención última, comunicarle que querían agasajar a su ejército regalándole grano y otros presentes. Entonces, tras haber dejado como guarnición a un número considerable de soldados, se les condujo, aparentando que se iban a hacer cargo de los regalos, a un lugar adecuado para los propósitos de los cántabros y astures y, allí, los asesinaron. Su alegría, sin embargo, duró poco tiempo, pues su país (chóra) fue devastado, algunos de sus castros (teíche) fueron quemados y, lo peor de todo, se les amputaron las manos a todos los cautivos, siendo, de tal modo, rápidamente sometidos».

\footnotetext{
44 Criado 1993, 46 ss.

45 García Quintela 1999-2000, pp. 201 ss.

46 Sánchez-Palencia (ed.) 2000, 105

47 Parcero 1995, 134-135.
} 


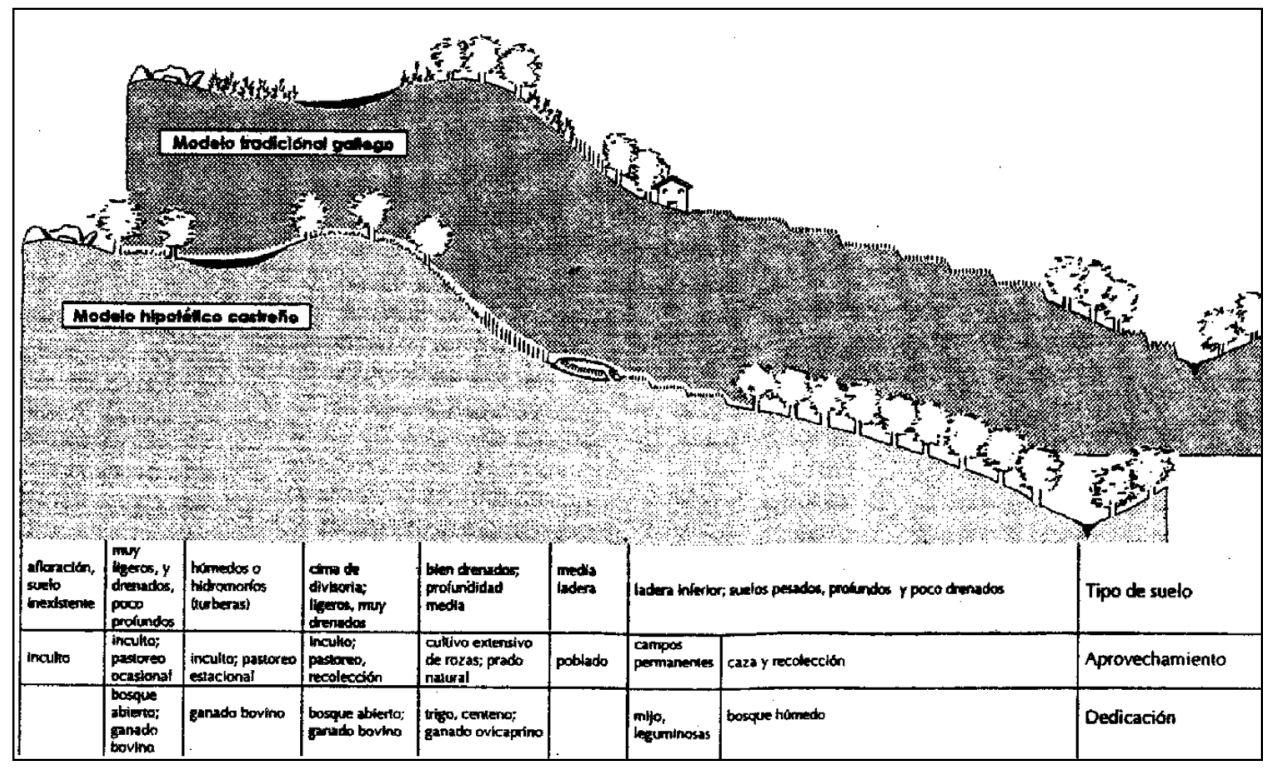

Figura 5. Modelo hipotético de utilización del medio natural en el NO en época castreña y comparación con modelo tradicional gallego (Fuente: Parcero 1995).

De este texto se puede deducir la existencia de un poblamiento organizado en torno a poblados amurallados (teíche), castros, es decir, de una chóra (territorio), como la denomina el texto, dedicada a la actividades agrícolas.

Todo parece indicar, por tanto, que a partir de la muralla se puede realizar una gradación del espacio según su carácter cultural que presenta estrechas características con la organización espacial, idéntica, que sabemos que funcionaba en el mundo griego antiguo. Es preciso, por tanto, que intentemos comprender estas categorías griegas, no sólo por su posible similitud con el espacio castreño sino también porque, a través de dicha aproximación, podemos llegar a comprender algunas de estas categorías utilizadas por Dion Casio en su texto.

En Grecia existe, en primer lugar, un espacio totalmente artificial y, por tanto, culturizado (oikouméne), que es el que ocupa el núcleo de habitación (la pólis). A continuación de esta primera área espacial, viene un espacio claramente cultural en tanto que transformado por la acción humana, aquel en el que se desarrolla la actividad agrícola (chóra); lo sigue otro espacio, escasamente culturizado pero en el que se testimonia la presencia de la actividad antrópica a través de una serie de practicas como la ganadería, la recolección, etc. y que actúa, además, como frontera entre las diferentes comunidades políticas, siendo también el ámbito en que se 
desarrolla la guerra y el entrenamiento e iniciación de los guerreros (la eskhatia o las eskhatiai $)^{48}$. Tras este espacio fronterizo se encuentra el espacio salvaje y no cultivado que, en Grecia, se conoce como agrós.

Esta organización y gradación del espacio es simplemente una manifestación de la diferenciación entre un espacio humanizado y otro no humanizado que, de hecho, parece caracterizar la concepción espacial de todas las sociedades humanas, posiblemente desde su más remota prehistoria ${ }^{49}$. Para el caso concreto de esta forma de organización y gradación espacial a partir de los campos cultivados y los no sometidos a acción antrópica, parece que se trata de un rasgo característico de todas las sociedades sedentarias y campesinas, si bien el carácter de dicha gradación puede variar entre las diferentes comunidades humanas ${ }^{50}$. Aún así, la antropología nos permite constatar que, en las sociedades agrícolas, la contraposición entre espacio salvaje - espacio civilizado se vincula con la actividad campesina, a partir de la cual se produce esa gradación entre espacios civilizados y salvajes. Parece, por tanto, que dicha polarización espacial varía según el tipo de actividad económica básica que caracteriza a las distintas sociedades humanas ${ }^{51}$. Estos hechos pueden explicar esta posible similitud entre el caso castreño y el caso griego. No obstante, lo que aquí nos interesa destacar es que los valores asignados a cada una de esas áreas espaciales que parece que podemos descubrir en el caso castreño se aproximan mucho a los que conocemos para el mundo griego.

Para llegar a establecer estos valores dentro del mundo del hierro del NO peninsular debemos aproximarnos a ciertas noticias de las fuentes antiguas que, de forma indirecta, nos hablan sobre esta gradación espacial entre naturaleza y cultura.

La exposición de los enfermos en los caminos y la lapidación de los parricidas mas allá de las montañas y de los cursos de agua de que nos habla Estrabón nos ofrecen claros indicios de limites espaciales de claro valor cultural dentro del mundo castreño ${ }^{52}$. En ambos casos se trata de acciones que se realizan fuera del

${ }^{48}$ Con respecto a estas categorías ver Vidal-Naquet, 1983; Snodgrass 1990, 87. Para el caso concreto de los valores de las eskhatiai ver Fernández Nieto 2001.

49 Paul-Lévy \& Segaud 1983, 37-38.

${ }^{50}$ Ver, a este respecto, las diferencias existentes entre las concepciones de la Atenas clásica, los gurmantché y gurunsi del Alto Volta o la sociedad campesina rumana que recogen Paul-Lévy \& Segaud 1983, 42-45.

51 Tal y como ha señalado Bermejo 1993, 19: «Para un pueblo de cazadores nómadas, por ejemplo para los pigmeos, el espacio civilizado era la selva, zona en la que vivían y de la que obtenían sus recursos, siendo el espacio salvaje el espacio cultivado, el espacio agrícola de sus pueblos vecinos, que les eran hostiles, mientras que la perspectiva del agricultor era exactamente la contraria».

52 «Despeñan a los condenados a muerte y a los parricidas los lapidan más allá de sus montañas y de sus ríos [es decir, de los límites de su territorio] (...) Exponen (protithéasin) a los enfermos en los 
territorio de la cultura, del espacio ocupado por la familia o por el grupo social. Siendo evidente, en el segundo de los casos, que lo que se pretende es preservar el espacio del grupo social puro, al margen de la enfermedad, transfiriendo ésta fuera del territorio, con la esperanza de que aquella se transmitiese a algún objeto inanimado ${ }^{53}$. Para ello, y al igual que sucedía en la Grecia antigua, se procede a exponer (protithemi) al enfermo, es decir, se le sitúa en un lugar que contrasta, como representante de un espacio lejano y salvaje, con el recinto de la casa y las tierras cultivadas de su alrededor, lejos de las casas, de las huertas y los campos, en la tierra inculta donde viven los rebaños, el espacio extranjero y hostil del agrós ${ }^{54}$.

El funcionamiento de los ríos como limites o fronteras dentro del mundo castreño del NO esta atestiguado gracias, por una parte, a la etnonimia prerromana, tal y como sucede en el caso de los Celtici Supertamarici y sus vecinos los Praestamarici, cuyas denominaciones derivan del hidrónimo Tamara (Tambre) que servía de límite entre $\operatorname{ambos}^{55}$. También gracias al hallazgo de material epigráfico: en la vega de Chaves (Portugal), a lo largo del curso del río Samaiôes, se ha descubierto una serie de hitos terminales alineados que separaban los territorios de los Preani y los Coroqui; del mismo modo, en O Rigueiral (Sanfins, Valpaços, Portugal) también se descubrió, sobre un cerro de poca altura a la vera de un regato, un término rupestre entre los Obilos y los Trebilos ${ }^{56}$. Todos estos datos parecen confirmar, por tanto, la noticia de Estrabón sobre el funcionamiento de los ríos como límites.

El registro arqueológico también nos permite constatar el funcionamiento de las áreas de montaña como límites dentro del ámbito cultural prerromano del NO. Esto parece ser, al menos, lo que ha constatado Carballo en el caso de la dorsal gallega que, en el sector comprendido entre el Valle del Deza y el Valle Medio del Miño, actuó como elemento de separación cultural entre ambas áreas ${ }^{57}$.

Sabemos además, gracias a Diodoro Sículo, que las montañas eran una de esas áreas de limite o frontera situadas al margen de la cultura; es decir, que se trataba

\footnotetext{
caminos, del mismo modo en que lo hacían los egipcios en tiempos antiguos, para que sean curados por aquellos que padecieron la misma enfermedad» (Estrabón, III, 3, 7).

${ }^{53}$ Con respecto a la finalidad de la exposición de enfermos ver Bermejo Barrera 1978, 79 y 1986, 195; para el caso del despeñamiento y la lapidación ver Bermejo Barrera 1978, 25 y 1986, 30; con respecto a estas formas de castigo capital en la antigüedad clásica ver Cantarella 1996, 68 ss., 85 ss., 220 ss. y 296 ss.

54 Tal y como señaló, para la Grecia antigua, Vidal-Naquet 1987, 170.

55 Tovar 1989, 137.

${ }^{56}$ Rodríguez Colmenero 1993, 11 y 15.

57 Ver Carballo 2003, 333 ss.
} 
de un espacio marcado por su claro carácter natural. Según Diodoro (V, 34, 6), en las partes más remotas de las montañas se reunían los lusitanos para constituir sus bandas de guerreros ${ }^{58}$. Parece, por tanto, que en el NO tenemos constatada la vinculación entre zonas salvajes (montes, bosques) y actividad guerrera que también se aprecia en la antigua Grecia.

Por lo demás, el tipo de guerra que parecen testimoniar las bandas de guerreros lusitanos y la guerra pre-hoplítica griega, la que, por ejemplo, se nos describe en Homero, parecen responder a un mismo modelo de conflicto y de actividad béli$\mathrm{ca}^{59}$. Es decir, estamos ante una forma de guerra caracterizada por el combate individual y no por la lucha en formación cerrada, como sería la típica de las falanges griegas o de las unidades legionarias romanas ${ }^{60}$. La arqueología, por lo demás, parece confirmar este dato gracias a la representación de la caetra entre la panoplia de los «guerreiros» galaico-lusitanos. Estrabón, como ya vimos, nos menciona que este pequeño escudo «no tiene, al parecer, abrazaderas ni asas» y la arqueología nos permite constatar estos datos, pues, en el centro de su cara interior existía una pequeña concavidad que servía para introducir el puño, permitiendo que la mano aferrase una manilla metálica que era la que permitía aguantar el escudo. Dado este sistema de agarre no se trata de un escudo cuya finalidad era proteger el cuerpo, sino que se utilizaría para, separado de aquél, realizar una defensa agresiva, manteniendo la caetra alejada del cuerpo, adelantándose para detener el golpe del contrario y replicar a continuación. Este uso adelantado del escudo con respecto al cuerpo implica el predominio del combate singular sobre la formación cerrada, pues la sustentación del escudo con el brazo extendido dificulta la constitución de un frente continuo, necesario para una formación del tipo de la falange ${ }^{61}$.

Así pues, esta visión desde la muralla del castro hacia el resto del territorio y del paisaje castreños nos ha permitido realizar un breve recorrido espacial que nos ha llevado desde las áreas de plena cultura hasta las de plena naturaleza. De la cultu-

58 «Existe una costumbre muy típica entre los íberos y, en especial, entre los lusitanos que consiste en que cuando los jóvenes alcanzan el esplendor de su fuerza física, aquellos de entre ellos más pobres en bienes terrenales, pero destacados por su vigor corporal y su osadía, se reúnen, pertrechados exclusivamente con su valor y sus armas, en las zonas más seguras de los montes, donde forman bandas de un tamaño considerable y recorren Iberia acumulando riquezas mediante el pillaje». Este pasaje, como ha señalado Ciprés 1993, 147-153, parece dar cuenta de un posible rito de paso vigente entre los lusitanos.

59 Ver Fernández Canosa 1987, 150 ss.; Bermejo 1986, 88 ss,; Ciprés 1993, 43 ss. y 137 ss.; Almagro Gorbea 1997, 207 y 217; García Quintela 1999, 179 ss. y 270 ss. Para el caso concreto de la Grecia homérica, véase Van Wees 1988 y 1994.

${ }^{60}$ Con respecto a las características del combate en formación cerrada, concretamente en falange, ver Hanson 1990.

${ }^{61}$ Descripción tomada de Gracia Alonso 2003, 205. 
ra, la muralla, hemos llegado hasta la naturaleza salvaje y, en ella, nos hemos encontrado con la actividad guerrera.

A partir de la consideración de las murallas de los castros como elementos de protección contra la naturaleza hostil nos hemos encontrado, como consecuencia de este breve e intuitivo excurso, con la actividad bélica. El espacio de la naturaleza es, como acabamos de ver, el ámbito de la guerra. Por tanto, proteger el espacio de la máxima cultura, el poblado, de los peligros de la naturaleza implica, a fin de cuentas, acotar, mediante una acción cultural de claro carácter monumental (la construcción de la muralla), un espacio para la paz y la máxima cultura (marcado por ser el ámbito en que se desarrollan las relaciones pacíficas entre grupos familiares, las tareas productivas, etc. que caracterizan el funcionamiento interno de cada comunidad) y separarlo de la naturaleza más extrema (el mundo de las bestias salvajes, el bosque, la caza y la guerra, pues es en él en el que se constituyen las bandas de guerreros). Monumentalizar el paisaje, acotar la cultura y la naturaleza a través de la construcción de la muralla es, a fin de cuentas, establecer dos ámbitos espaciales distintos y segregados, de tal modo que si se separa a la cultura de la naturaleza también se está intentando aislar la paz social interna de la comunidad del conflicto externo (la guerra) con otras comunidades.

Las murallas, por tanto, parecen ser defensivas y lo son en toda la extensión de la palabra, defendiendo a la comunidad que se refugia dentro de ellas no sólo del ataque de otras poblaciones sino también de cualquier otro posible ataque, como, por ejemplo, el del medio natural. Parece, en conclusión, que los argumentos expresados en contra del carácter defensivo de las murallas de los castros tampoco son concluyentes y definitivos y que, con ellos, únicamente se quiere dar cobertura a esa negación del papel desempeñado por la actividad bélica dentro del mundo castreño, actividad que, en opinión de los detractores del valor defensivo de las murallas, resulta peligrosa porque suena a celtista y porque el registro, siempre omnipresente y omnivalente para estos autores, parece negarla. Sin embargo, cuando se excava un castro ¿hay acaso algún otro elemento arqueológico de mayor tamaño e importancia que la muralla? Creo que no y, a este respecto, el registro me parece que es significativo: los habitantes de los castros construían murallas para defenderse, en el más amplio sentido de la palabra. Si un sector de la investigación niega el carácter defensivo de estas construcciones, ello se debe, como ya hemos indicado, a que se trata de un rasgo que no coincide con su hipótesis inicial, lo que lleva a estos autores a criticar el carácter defensivo de las murallas y a buscar complejas explicaciones que les permitan explicar la construcción de dichos elementos.

Cierro, ya, las presentes páginas. Pero, antes de hacerlo, deseo volver a un argumento que ya he señalado anteriormente. Me refiero a esa potenciación, defendida 
por algunos autores ${ }^{62}$, del dato arqueológico como el más óptimo, por su carácter aséptico, para poder reconstruir la verdad histórica objetiva. En estas páginas he intentado demostrar que el dato arqueológico, en realidad, no es aséptico, que la interpretación del registro depende, al igual que todas las observaciones, de una teoría que lo sostenga y lo dote de significado, pues, de otro modo, sólo tendríamos datos inconexos. Así pues, y a diferencia de lo que opinan quienes defienden afirmaciones como la anterior, creo que la mejor reconstrucción histórica es aquella que tiene en cuenta una mayor cantidad de datos de diverso origen y que sabe, a partir de ellos y de su correcta crítica e interpretación, desarrollar una hipótesis explicativa. Frente a esta omnipresencia del dato arqueológico, defiendo una explicación de la cultura castreña del NO que tenga en cuenta los datos arqueológicos y los datos que nos ofrecen, una vez sometidas a crítica, las fuentes antiguas, una interpretación que, frente al aislamiento a que se ha visto sometido el mundo del hierro del NO peninsular, defienda su contextualización y la de todos los datos que sobre él podamos extraer dentro de otros ámbitos culturales del hierro peninsular y europeo a través del recurso a una comparación bien hecha. Este planteamiento implica, evidentemente, plantearse nuevas preguntas y desarrollar nuevas estrategias de investigación que permitan construir nuevas hipótesis explicativas. Este es, en mi opinión, el reto que se plantea a todos los prehistoriadores, arqueólogos e historiadores de la Antigüedad sí quieren llegar a comprender y explicar la sociedad y el mundo de la Edad del Hierro del Noroeste de la Península Ibérica.

\section{BIBLIOGRAFÍA}

ALMAGRO GORBEA, M., 1997: «Guerra y sociedad en la Hispania céltica», en La guerra en la Antigüedad. Una aproximación al origen de los ejércitos en Hispania, Madrid, 207-221.

ÁLVAREZ SANCHÍS, J. R., 2003: Los señores del ganado. Arqueología de los pueblos prerromanos en el Occidente de Iberia, Madrid.

BAQUEDANO BELTRÁN, M. I \& CABRÉ DE MORÁN, E., 1997: «Caudillos celtas y armamento de parada», en La guerra en la Antigüedad. Una aproximación al origen de los ejércitos en Hispania, Madrid, 261-269.

BELlO DiÉGUEZ, J. M. \& PEÑA SANTOS, A. de la, 1995: Galicia na Prehistoria. Historia de Galicia. Tomo I, Perillo-Oleiros (A Coruña).

BERMEJO, J. C., 1978: La Sociedad en la Galicia Castreña, Santiago, 1978.

- 1986: Mitología y mitos de la Hispania Prerromana. II., Madrid.

${ }^{62}$ Como, por ejemplo, expresamente lo manifiesta Peña 2003, 110. 
1993: «Sobre las dimensiones significativas del espacio», Concepcións espaciais e estratexias territoriais na Historia de Galicia, Santiago, pp. 5-22.

- 2002: «Sobre el buen uso de los monumentos arqueológicos», Gerión, 20 (1), pp 11-32

BETTENCOURT, A. M. S., 2000: «O mundo funerario da Idade do Ferro do Norte de Portugal: algumas questôes», III Congreso de Arqueología Peninsular. Setembro 1999. Actas, vol. 5, Porto, 4359.

BRAÑAS, R. \& COMENDADOR, B., 2003: «Espadas cortas de antenas no Castelo de San Antón», Boletín dos Amigos do Arqueolóxico Coruña. 6, 31-35.

BRAUND, D., 1984: Rome and the friendly King, Londres.

BRUN, P., 2002: «El torques en Europa», en Torques, belleza y poder, Madrid, 47-58.

BRUNAUX, J.-L. \& LAMBOT, B., 1987: Guerre et armament chez les gaulois (450-52 av. J.-C.), París.

CABRÉ DE MORÁN, E. \& BAQUEDANO BELTRÁN, M. I., 1997: «El armamento céltico de la segunda Edad del Hierro», en La guerra en la Antigüedad. Una aproximación al origen de los ejércitos en Hispania, Madrid, 240-259.

CALO LOURIDO, F., 1993: A Cultura Castrexa, Vigo.

- 1994: A plástica na cultura castrexa galego-portuguesa, A Coruña.

- 1997: «A síntese: o galaico romano», en Pereira Menaut, G. (coord.), Galicia fai dous mil anos. O feito diferencial galego, vol. I, Santiago de Compostela, 193-212.

CANTARELLA, E., 1996: Los suplicios capitales en Grecia y Roma. Orígenes y funciones de la pena de muerte en la antigüedad clásica, Madrid.

CARBALLO ARCEO, L. X., 2003: «La Dorsal gallega como barrera intracultural durante la Edad del Hierro», Madrider Mitteilungen, 44, pp. 333-345.

CERDEÑO SERRANO, M. L., 1997: «Sistemas defensivos en el ámbito celta peninsular», en La guerra en la Antigüedad. Una aproximación al origen de los ejércitos en Hispania, Madrid, 231-239.

CIPRÉS, P., 1993: Guerra y sociedad en la Hispania indoeuropea, Vitoria.

CLASTRES, P., 1974: «Echange et pouvoir: philosophie de la chefferie indienne», en Clastres, P., La Société contre l'État. Recherches d'Anthopologie Politique, París, pp. 25-42.

CRIADO, F., 1993: «Espacio monumental y paisajes prehistoricos en Galicia», Concepcións espaciais e extratexias territoriais en Galicia, Santiago, pp. 23-54.

CUNLIFFE, B., 1997: The Ancient Celts, Londres.

DIODORO SÍCULO: Diodorus of Sicily in twelve volumes, t. III, Cambridge (Mass.) \& Londres, 1970.

DIÓN CASIO: Dio's Roman History in nine volumen, t. VI, Cambridge (Mass.) \& Londres, 1980.

ESTRABÓN: The Geography of Strabo in eight volumes, t. II, Cambridge (Mass.) \& Londres 1969.

FERNÁNDEZ CANOSA, A., 1987: «As maneiras de combate na Lusitana», Trábalhos de Antropología e Etnología, 27, 1987, pp. 149-159. 
FERNÁNDEZ NIETO, F. J., 2001: «Frontera como límite y barrera: el valor religioso y mágico del límite en la cultura griega», en López Barja, P. y Reboreda Morillo, S. (eds.), Fronteras e identidad en el mundo griego antiguo, Santiago de Compostela-Vigo, pp. 227-240.

GARCÍA HUERTA, R., 1997: «La guerra entre los pueblos célticos. Las fuentes literarias grecolatinas», en La guerra en la Antigüedad. Una aproximación al origen de los ejércitos en Hispania, Madrid, 223-229.

GARCÍA QUINTELA, M. V., 1999: Mitología y mitos de la Hispania Prerromana III, Madrid..

- 1999-2000: «La construcción del espacio entre íberos y celtíberos», Kalathos, 18-19, pp. 201-240.

- 2002: La organización socio-política de los populi del Noroeste de la Península Ibérica. Un estudio de antropología política histórica comparada. Traballos de Arqueoloxía e Patrimonio (TAPA), 28, Santiago de Compostela.

GARCÍA RIAZA, E., 2002: Celtíberos y lusitanos frente a Roma: diplomacia y derecho de guerra, Vitoria.

GONZÁLEZ GARCÍA, F. J.: En Prensa: «Los Celticos de Gallaecia: Apuntes sobre etnicidad y territorialidad en la Edad del Hierro del Noroeste de la Península Ibérica, Complutum.

GONZÁLEZ RUIBAL, A.: 2003: Arqueología del Primer Milenio antes de Cristo en el Noroeste de la Península Ibérica, Tesis Doctoral inédita, Madrid.

GRACIA ALONSO, F., 2003: La guerra en la protohistoria. Héroes, nobles, mercenarios y campesinos, Barcelona.

GUILAINE, J. \& ZAMNIT, J., 2002: El camino de la guerra. La violencia en la prehistoria, Barcelona (París, 2001).

HANSON. V.D., 1990: Le modele occidental de la guerre, París.

JAMES, S., 1999: The Atlantic Celts. Ancient people or modern invention?, Londres.

JAMES, S. \& RIGBY, V., 1997: Britain and the Celtic Iron Age, Londres.

KEEGAN, J., 1995: Historia de la guerra, Barcelona.

KRISTIANSEN, K., 1999: «The emergence of warrior aristocracies in Later European Prehistory and their long.term History», en J. Carman \& A. Harding, Ancient Warfare. Archaeological Perspectives, Londres, 175-189.

LE BOHEC, Y., 1990: L’armée romain sous le Haut-Empire, París, 1990.

LE ROUX, P., 2003: «À la recherche del élites locales: le Nord-Ouest hispanique», en M. CébeillacGervasoni \& L. Lamoine, Les élites et leurs facettes. Les élites locales dans le monde hellénistique et romain, Roma - Clermont-Ferrand, 171-186.

LÉVI-STRAUSS. C., 1984: El pensamiento salvaje, México.

LEWUILLON, S., 1999: Vercingétorix ou le mirage d'Alésia, Bruselas.

LÓPEZ CUEVILLAS, F., 1947: «Armería posthallstáttica del NO hispánico», Cuadernos de Estudios Gallegos, VIII, 543-589.

- 1989: La civilización céltica en Galicia, Madrid (ed. orig., Santiago de Compostela, 1953). 
LORRIO, A. J., 1993: «El armamento de los celtas hispanos», en M. Almagro Gorbea (dtor.), Los celtas: Hispania y Europa, Madrid, 285-326.

MANGAS, J., 2000: «Castellum, gens y civitas en el Edicto de Augusto», en Sánchez-Palencia, F.J. \& Mangas, J. (Coords.), El Edicto del Bierzo. Augusto y el Noroeste de Hispania, Ponferrada, 4762.

MARCO SIMÓN, F., 2002: «El torques como símbolo», en Torques, belleza y poder, Madrid, 69-79.

MARTINS, M. \& JORGE, S.O., 1992: «Substrato cultural das etnias pré-romanas do Norte de Portugal», en M. Almagro Gorbea y G. Ruiz Zapatero, Paleoetnología de la Península Ibérica. Complutum, 2-3, 347-372.

MEIJIDE CAMESELLE, G., 1988: Las espadas del Bronce Final en la Península Ibérica, Santiago de Compostela.

OLIVIER, L., 2002: «El torques como adorno personal», en Torques, belleza y poder, Madrid, 81-85.

PARCERO, C., 1995: «Elementos para el estudio de los paisajes castreños del Noroeste peninsular», Trabajos de Prehistoria, 52, pp. 127-144.

PAUL-LÉVY, F. \& SEGAUD, M., 1983: Anthropologie de l'espace, París.

PEÑA, A. de la, 1992: «El primer milenio a.C. en el área gallega: Génesis y desarrollo del mundo castreño a la luz de la arqueología», en M. Almagro Gorbea y G. Ruiz Zapatero, Paleoetnología de la Península Ibérica. Complutum, 2-3, 373-394.

- 1996: «A secuencia cultural do mundo castrexo galaico», en J.M. Hidalgo Cuñarro (coord.), A Cultura Castrexa a debate, Tui, 63-103.

- 1997: «Os pobos castrexos antes da conquista romana», en Pereira Menaut, G. (coord.), Galicia fai dous mil anos. O feito diferencial galego, vol. I, Santiago de Compostela, 143-191.

- 2003: Galicia. Prehistoria, castrexo e primeira romanización, Vigo.

PEREA, A., 2003: «Los torques castreños en perspectiva», Brigantium, 14, 139-149.

PÉREZ VILATELA, L., 2000: Lusitania. Historia y etnología, Madrid.

POLIBIO: Historias. Libros I-IV, introducción de A. Díaz Tejera, traducción y notas de M. Balasch Recort, Madrid, 1981.

QUESADA SANZ, F., 1997a: «Algo más que un tipo de espada: la falcata ibérica», en La guerra en la Antigüedad. Una aproximación al origen de los ejércitos en Hispania, Madrid, 196-205.

- 1997b: «Montefortino-type and related helmets in the Iberian Peninsula: a study in archaeological context», Journal of Roman Military Equipment Studies, 8, 151-166.

RAFTERY, B., 1994: Pagan Celtic Ireland. The enigma of the Irish Iron Age, Londres.

REINACH. S., 1996: «Un mythe né d'un rite. L'épée de Brennus», en S. Reinach, Cultes, mythes et religions, París, 302-315 (ed. original: L'Anthropologie, 1906, 321-336).

RODRÍGUEZ COLMENERO, A., 1993: Corpus-catálogo de Inscripciones Rupestres del Cuadrante Noroeste de la Península, Larouco, Anejo 1.

ROLDÁN HERVÁS, J. M., 1997: «Los hispanos en el ejército romano», en La guerra en la Antigüedad. Una aproximación al origen de los ejércitos en Hispania, Madrid, 299-309. 
SÁNCHEZ MORENO, E., 2001: «Algunas notas sobre la guerra como estrategia de interacción social en la Hispania prerromana: Viriato, jefe redistributivo (I)», Habis, 32, 149-169.

- 2002: «Algunas notas sobre la guerra como estrategia de interacción social en la Hispania prerromana: Viriato, jefe redistributivo (y II)», Habis, 33, 141-173.

SÁNCHEZ-PALENCIA, F. J. (ed.), 2000: Las Médulas (León). Un paisaje cultural de la «Asturia Augustana», León.

SÁNCHEZ-PALENCIA, F. J. \& MANGAS, J. (coords.), 2000: El Edicto del Bierzo. Augusto y el Noroeste de Hispania, Ponferrada.

SANTOS YANGUAS, N., 1988: El ejército y la romanización de Galicia, Oviedo.

SASTRE PRATS, I., 2001: Las formaciones sociales rurales de la Asturia romana, Madrid.

SNODGRASS, A., 1990: Arqueología de Grecia. Presente y futuro de una disciplina, Barcelona.

STARY, P. F., 1982: «Keltische Waffen auf der Iberischen Halbinsel», Madrider Mitteilungen, 23, 114144.

TEIRA BRIÓN, A. M., 2003: «Os traballos agrarios e as ferramentas empregadas na cultura castrexa», Gallaecia, 22, 157-192.

TOVAR, A., 1989: Iberische Landeskunde. Segunda parte. Las tribus y las ciudades de la Hispania Antigua. Tomo 3. Tarraconense, Baden-Baden.

TRANOY, A., 1988: «Du heros au chef. L'image du guerrier dans les sociétés indigènes du NordOuest de la Péninsule Ibérique (II siècle avant J.-C. - ${ }^{\mathrm{er}}$ siécle après J.-C.)», en Le mond des images en Gaule et dans les provinces voisines, Caesarodonum, XXIII, 219-227.

VAN WEES, H., 1988: «Kings in combat: battles and heroes in the Iliad», Classical Quarterly, 38, 124.

- 1994: «The homeric way of war: the Iliad and the hoplite phalanx (I \& II)», Greece and Rome, XLI (1-2), 1-18 y 131-155.

VÁZQUEZ VARELA, J. M. \& GARCÍA QUINTELA, M. V., 1998: A vida cotiá na Galicia castrexa, Santiago.

VIDAL-NAQUET, P., 1983: Formas de pensamiento y formas de sociedad en el mundo griego. El cazador negro, Barcelona.

- 1987: «El Filoctetes de Sófocles y la efebía», en Vernant. J.-P. y Vidal Naquet, P., Mito y Tragedia en la Grecia antigua. I. Madrid.

VILASECO VÁZQUEZ, X. I., 1999: «A problemática dos enterramentos na Cultura Castrexa do NW. Unha aproximación desde as culturas limítrofes», Revista de Guimarâes, vol. esp. II, 495-513.

WELLS, P.S., 2001: The barbarians speaks. How the conquered peoples shaped Roman Europe, Princeton \& Oxford.

- 2002: Beyond celts, germans and scythians, Londres. 
